\title{
Influence of SR-90 on the Morphometric Indices and the Level of Proteins of Metallothioneins in the Soft Tissues of Terrestrial Mollusks Bradybaena Fruticum in the Area of Location of the Regional Radioactive Waste Storage Facility
}

\section{Lavrentyeva G. ${ }^{1}, 2$, Shoshina R. ${ }^{1}$, Mirzeabasov 0. ${ }^{1}$, and Synzynys B. ${ }^{1}$}

${ }^{1}$ National Research Nuclear University MEPhl (Moscow Engineering Physics Institute), Kashirskoe shosse 31, Moscow, 115409, Russia

${ }^{2}$ Bauman Moscow State Technical University (Kaluga Branch), Kaluga, Russia

Corresponding Author: Galina Lavrentyeva Lavrentyeva_G@list.ru

Received: 17 January 2018 Accepted: 25 March 2018 Published: 17 April 2018

Publishing services provided by Knowledge $\mathrm{E}$

(c) Lavrentyeva G. et al. This article is distributed under the terms of the Creative Commons Attribution License, which permits unrestricted use and redistribution provided that the original author and source are credited.

Selection and Peer-review under the responsibility of the PhysBioSymp17 Conference Committee.

\section{Abstract}

The concept of "conditional or reference animals and plants" proposed by the ICRP is the most developed in the development of an ecocentric radiation protection strategy. At the same time, the set of 12 reference species proposed by the ICRP is not final, which requires justification of other representatives of the biota for inclusion in the reference set, including taking into account the formation of dose loads and radiationinduced effects. In this work it was estimated the effect of irradiation of land mollusks of the species Bradybaena fruticum with the radionuclide Sr-90 on the morphometric parameters of shellfish (height and diameter of the shell) and the level of proteins of metallothioneins in the field experiment. The absorbed dose rate of the mollusk was calculated using the Monte Carlo method (taking into account the scenario of self-irradiation, irradiation from $\mathrm{Sr}-90$ accumulated in the soil and accumulated in the nettle). In the range of doses studied it was established reliable radiation-induced change in the height of shell and the level of proteins metallothioneins in the soft bodies of a mollusk of the species Bradybaena fruticum.

Keywords: mollusc of the species Bradybaena fruticum, absorbed dose rate, height of shell, diameter of shell, proteins of metallothioneins

\section{Introduction}

The concept of "conditional or reference animals and plants" proposed by the ICRP is the most developed in the development of an ecocentric radiation protection strategy 
[1]. At the same time, the set of 12 reference species proposed by the ICRP is not final, which requires justification of other representatives of the biota for inclusion in the reference set, including taking into account the formation of dose loads and radiation-induced effects. In this work it was estimated the effect of irradiation of terrestrial mollusks of the species Bradybaena fruticum with the radionuclide Sr-90 on the morphometric parameters of shellfish (height and diameter of the shell) and the level of proteins of metallothioneins (protein MT) in the field experiment. The site for research is the biotope of the regional storage of radioactive waste in the Kaluga region. In 1998 it was found that one of the storage tanks and leakage of radionuclides depressurized. As a result, an uncontrolled source of radionuclides entering the ecosystem components was formed in the soil. On the basis of many years of research it has been established that the radioecological situation in the study area is due to Sr-9o [2].

\section{Materials and methods}

\subsection{Sample selection}

Soil samples were collected in 42 local controlled areas using a specialized sampler with a set of Edelman's handled soil drills.

Samples of Bradybaena fruticum mollusks were sampled from nettles and from soil under plants. Samples of middle-aged mollusks in the number of 25-30 specimens from one local site were sampled. In view of the fact that preference is given to calciferous plants in the foraging base of mollusks, a nettle (Urtíca dióica) sample was sampled.

\subsection{Determination of the specific activity of $\mathrm{Sr}-90$ and the concentration of heavy metals in ecosystem components}

Measurement of specific activity of Sr-90 with preliminary radiochemical isolation of $\mathrm{Sr}-90$ in samples of soil, plants and terrestrial mollusks was carried out on a scintillation beta spectrometer BETA-01C according to the standard procedure for determining Sr90 content from the beta radiation of its daughter radionuclide $Y-90$ in environmental objects (3).

The concentration of heavy metals ( $\mathrm{Ni}, \mathrm{Zn}, \mathrm{Mn}, \mathrm{Cu}, \mathrm{Pb}, \mathrm{Co}, \mathrm{Cd}, \mathrm{Cr}, \mathrm{Fe}$ ) in soil extracts was measured by atomic emission with inductively coupled plasma (ICP AES Varian Liberty II). It was found that the concentration of heavy metals does not exceed the 
established MPC in the soil of controlled areas, and does not exceed the corresponding concentration in the soil of the control section.

Determination of the specific activity of $\mathrm{Sr}-90$ and concentration of heavy metals in each sample was carried out in triplicate.

The control area with Sr-90 specific activity in soil of $20 \pm 3 \mathrm{~Bq} / \mathrm{kg}$ and with a uniform concentration of heavy metals (compared to the soils of the studied local areas) was selected.

\subsection{Calculation of annual exposure doses for molluscs}

An estimate of the absorbed dose rate for the terrestrial mollusk was performed using the Monte Carlo method. The following exposure scenarios were taken into account: self-irradiation from Sr-9o deposited in the shell of the body; irradiation from Sr-90 in the soil when the mollusk lives on the soil surface during the growing season (210 days per year) and in the soil in the state of suspended animation (155 days per year); irradiation from Sr-9o contained in plants.

\subsection{Determination of morphometric parameters and the level of proteins of metallothioneins}

Measurement of the morphometric parameters (height of shell, diameter of shell) was performed using a binocular microscope. The level of protein MT in the tissues of molluscs was determined by a radiochemical method based on the replacement of metal ions with radioactive $\mathrm{Cd}-109$ chelated in MT.

Statistical processing of the experimental data was carried out using the program R.

\section{Results and discussion}

Based on the calculation of the dose load for terrestrial mollusks by means of the Monte Carlo method (taking into account the scenario of self-irradiation, irradiation from Sr-9o accumulated in the soil and accumulated in the nettle), it has been established that the absorbed dose rate of the mollusk varies in the range from $0.32 \pm 0.07$ to $76 \pm 18 \mathrm{mGy} /$ year.

In this work the morphometric characteristics of the mollusk (height and diameter of the shell) and the level of protein-MT in soft bodies in response to an increase in the radiation dose rate were studied. At the same time, a significant change in the 
heightof shell and protein-MT level was established, in contrast to the diameter of the shell, which has no response in the studied range of dose rates.

A change in the height of the shell of the mollusk is established with an increase in the absorbed radiation dose rate, which is described by an equation of the form $y=$ $0.5+0.06 x e(-0.04 x)(p<0.05)($ Fig.1).

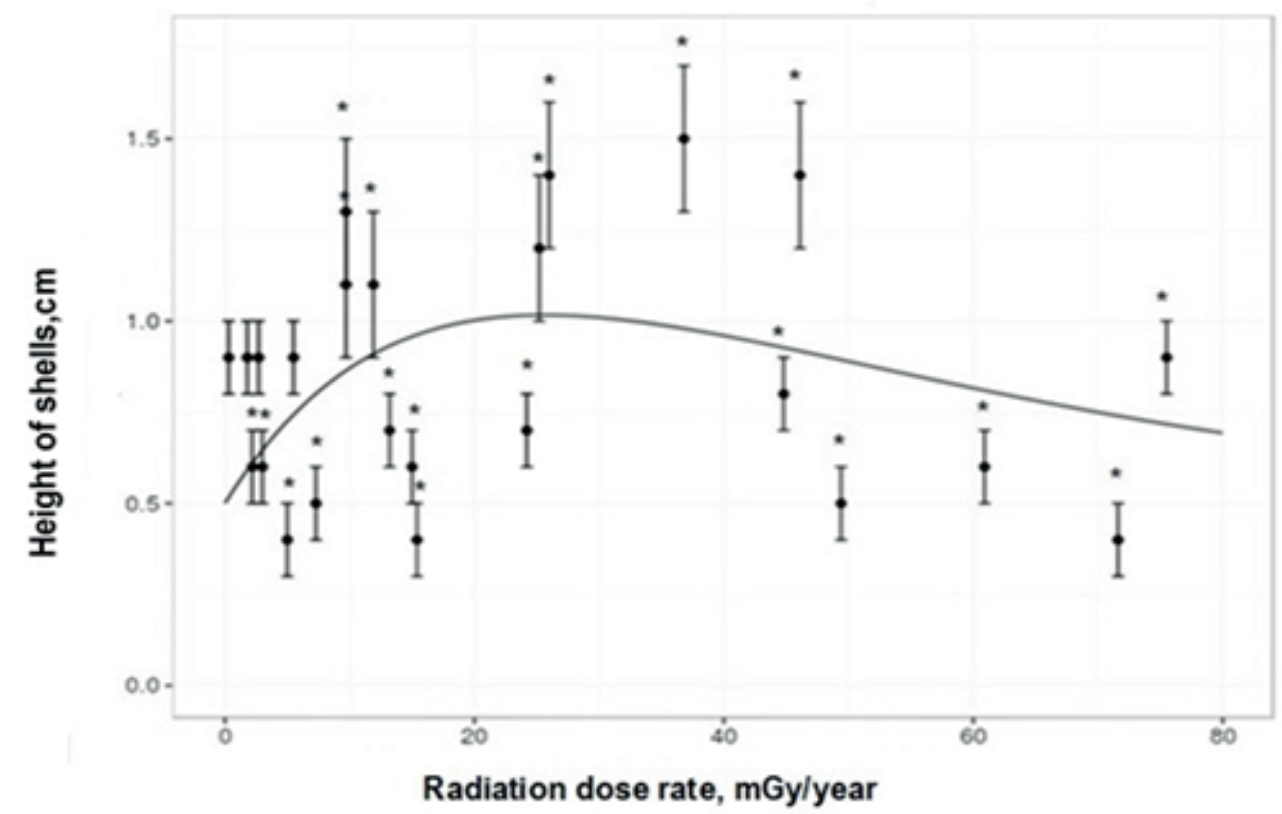

Figure 1: Dependence of the change in height of shell on the absorbed dose rate of irradiation of land mollusks.

An increase in the index from $0.41 \pm 0.06$ to $1.5 \pm 0.3 \mathrm{~cm}$ is observed up to the power of the absorbed dose of mollusc irradiation of $37 \pm 6 \mathrm{mGy} /$ уг. With further increase in the absorbed radiation dose of $\mathrm{Sr}-90$ mollusks, and the height of the shell is reduced to $0.41 \pm 0.06 \mathrm{~cm}$, keeping the lower values up to doses of $76 \pm 18 \mathrm{mGy} /$ year. It should be noted that a number of factors, including climatic (habitat temperature, humidity), population density, the age of mollusks, and the pollution of their habitat can influence the change in the morphometric indices of terrestrial mollusks, in particular the shape and size of the shell. These factors are excluded due to specificity of the experiment.

On the basis of the foregoing, and also taking into account the heterogeneity of the radioactive contamination of the study area in comparison with the control site (the $\mathrm{Sr}-90$ specific activity in the soil varies in the range $1.5 \pm 0.2-5203 \pm 785 \mathrm{~Bq} / \mathrm{kg}$, in plants - from $5.8 \pm 0.9$ to $13311 \pm 2013 \mathrm{~Bq} / \mathrm{kg}$ ), which in turn determines the different levels of irradiation of the studied organisms, it is possible to assume the radiative nature of the detected changes in the height of shells of land mollusks of the species Bradybaena fruticum. 
A similar assumption is possible with regard to the change in the level of proteins MT in soft tissues of mollusks from $12.4 \pm 1.4$ to $57 \pm 9 \mu \mathrm{g} / \mathrm{g}$ with an increase in the dose loading on the body, which is described by a piecewise linear relationship (Figure 2) of the form $y=a+k(x b)(p<0,05)$, where $a$ is the constant value to the threshold $(19,3)$, b is the critical (threshold) value of the absorbed dose rate ( $42.3 \mathrm{mGy} /$ year), $\mathrm{k}$ is the coefficient proportionality in the linear response region (1.12) $(p<0.05)$.

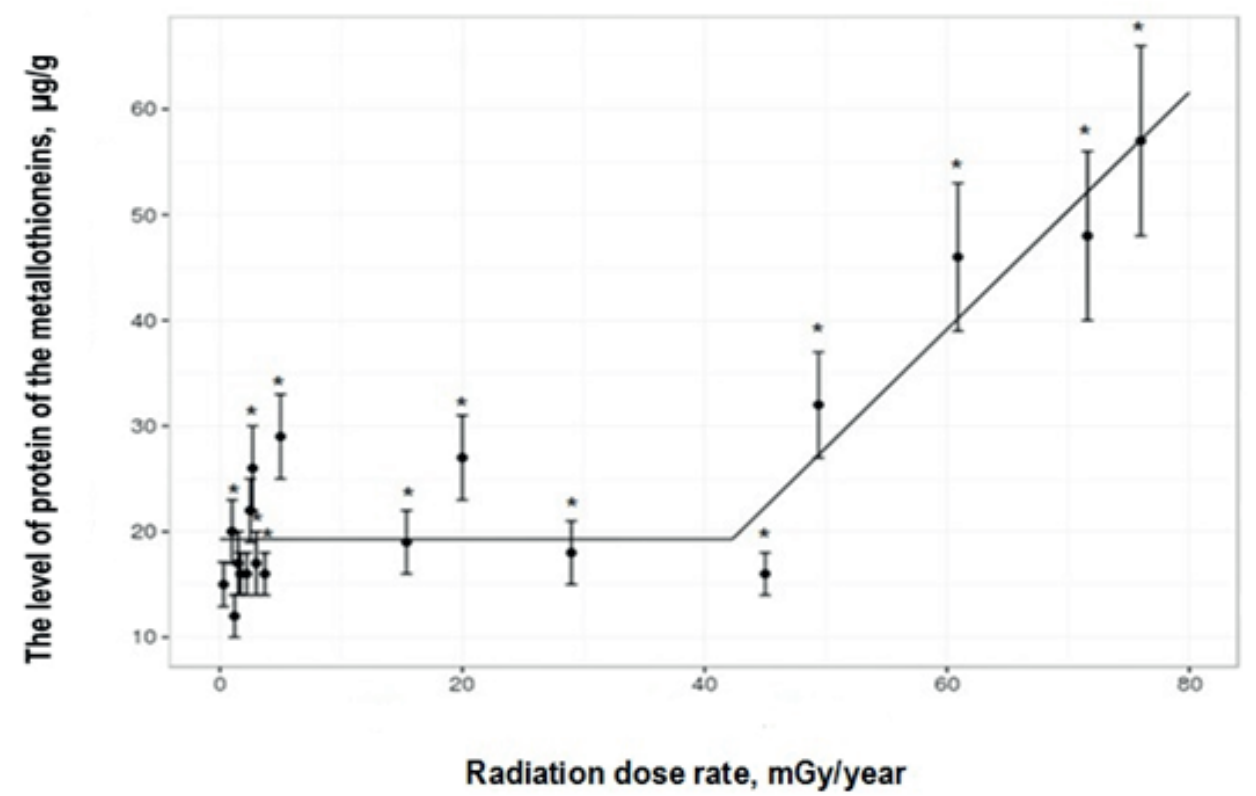

Figure 2: Change in protein-MT levels in soft bodies of mollusks depending on the dose load on the organism formed by Sr-9o.

According to this model, a dose-independent plot is noted at dose rates of $0.38 \pm$ $0.02-42.3 \pm 5.8 \mathrm{mGy} / \mathrm{yr}$, where the level of protein-MT synthesis does not change, which may indicate the body's ability to establish homeostasis by detoxifying the formed oxyradicals. While at higher dose loads ( $46 \pm 7$ - $76 \pm 18 \mathrm{mGy} / \mathrm{yr}$ ) monotonous linear growth of the level of proteins MT in soft tissues of terrestrial mollusks Bradybaena fruticum is observed, which may indicate the accumulation of a radionuclide in the body of mollusks and the development of oxidative stress.

It should be noted that the effect of heavy metals on the level of protein MT in the soft tissues of mollusks in the studied area is excluded due to the uniformity of the contamination.

\section{Conclusion}

The current situation with regard to radiation safety of biota requires solving problems related to the assessment of the effects of ionizing radiation on the parameters of 
living organisms, including genetic, reproductive, morphometric indicators, behavioral activity, etc. In laboratory and field studies, an important aspect is the choice of an indicator capable of quantitative (for the purpose of constructing dose-effect dependences) to characterize the degree and biological effect under the influence of the radiation factor.

Within the framework of the study, a significant radiation-induced change in the height of shell and protein MT level in the dose range of mollusc irradiation doses from $0.32 \pm 0.07$ to $76 \pm 18 \mathrm{mGy} / \mathrm{y}$ r was established. It was revealed that the mollusk of the species Bradybaena fruticum is a bioindicator of the radioactive contamination of the terrestrial ecosystem under the conditions of minor radioactive contamination of the ecosystem by radioactive strontium.

\section{Acknowledgments}

The work was carried out with partial financial support of Russian Foundation for Basic Research (contract No HK 15-38-20142/15).

\section{References}

[1] ICRP Publication 91. A framework for assessing the impact of ionizing radiation on non-human species, vol. 33, pp. 21-75, 2003.

[2] Lavrentyeva G.V. Characteristic of pollution with groundwater inflow ${ }^{90} \mathrm{Sr}$ natural waters and terrestrial ecosystems near a radioactive waste storage. Journal of Environmental Radioactivity, vol. 135, Pp. 128-134, 2014.

[3] Instruction : Procedure of radiochemical strontium-90 assessment in soil and plant samples, 1994. Instruction of Rosleskhoz of Russia from 05.09.1994 № 192. Moscow (in Russian). 